\title{
Polarization insensitive switchable metamaterial absorber/reflector for X-band applications
}

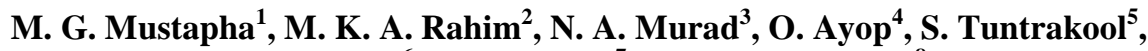 \\ M. A. Baba' ${ }^{6}$ A. Y. Iliyasu ${ }^{7}$, Mohd Ezwan Jalil ${ }^{8}$ \\ $1,2,3,4,6,7,8$ Advance RF and Microwave Research Group, School of Electrical Engineering, Faculty of Engineering, \\ Universiti Teknologi Malaysia, Johor, Malaysia \\ ${ }^{5}$ Facutly of industrial Education and Technology, King Mongkut Institute of Technology Ladkrabang (KMITL), \\ Bangkok, Thailand
}

\begin{tabular}{l} 
Article Info \\
\hline Article history: \\
Received Jan 31, 2020 \\
Revised Apr 15, 2020 \\
Accepted May 4, 2020 \\
\hline Keywords: \\
Absorber \\
AMC \\
Metamaterials \\
Reflector \\
Switchable
\end{tabular}

\begin{abstract}
A unit cell of squared shaped polarization-insensitive switchable metamaterial absorber/reflector is presented. The structure operates at $10.20 \mathrm{GHz}$ under both absorber mode and reflector mode configurations. Copper wire bridging the gaps to form a circular shape structure were used as switches for operation mode selections. The structure was designed on an FR4 substrate, and the incidental wave angles were varied from 0 to 50 degrees. The structure demonstrated almost $100 \%$ absorption at resonance, $3.314 \mathrm{GHz}$ percentage bandwidth at $80 \%$ as an absorber. On the other hand, as reflector, it demonstrated almost a $90 \%$ reflection and a usable bandwidth of $3.327 \mathrm{GHz}$.
\end{abstract}

This is an open access article under the $\underline{C C B Y-S A}$ license.

\section{Corresponding Author:}

M. G. Mustapha,

Advance RF and Microwave Research Group,

School of Electrical Engineering, School of Electrical Engineering,

Universiti Teknologi Malaysia,

81310 Johor Bahru, Johor, Malaysia.

Email: mmgajibo@yahoo.com

\section{INTRODUCTION}

The metamaterial (MTM) as defined, are structures artificially engineered to have properties not found in nature [1-3]. MTMs are divided into classes and subclasses. In the field of electromagnetic, the most important is left-handed metamaterial (LHM) [4], double negative (DNG) [5-7], backward media (BWM) [8] or negative index materials (NIM) [9]. Materials in this class exhibit negative permittivity and permeability simultaneously. This class is desirable in the electromagnetic field because in this class, waves can propagate in opposite directions which can be manipulated to increases the focusing/directivity of the propagated waves [10]. Other applications that can benefit from metamaterials are cloaking [11], reflectors [12], sensing, EM filters [13], focus antenna beam [14], low profile ground plane, phase shifting [15], etc.

Electromagnetic waves (EMW) absorber is defined as a structure that is capable of absorbing incidental waves by minimizing reflection and transmission through maximizing energy loss within the structure. In contrast, electromagnetic wave reflector or artificial magnetic conductor (AMC) are structures designed with unusual boundary conditions that are "selective" in supporting surface wave currents. Before the discovery of planar structures for absorbers and reflectors, Conventional absorbers and reflectors were in existence, but they all have their drawbacks, take, for instance, the Salisbury [16] and Dallenbach [17] have limitations of being narrowband and electrically thick. In addition to that, also, they can only operate in quarter wavelength [18]. Similarly, the conventional reflectors, known as perfect electric conductor (PEC) mainly used for antenna ground planes, have drawbacks. These drawbacks include 
the production of out of phase image currents and propagation of surface current. In this paper, replacing PEC with AMC counters these drawbacks and improves gain by reducing back radiation is presented.

\section{RESEARCH METHOD}

The proposed MTM structure is based on the designs presented in [12, 19, 20-25]. It is made up of four-square patches diagonally dissected to form two back-facing triangles each. In addition to that, the structure has eight copper wire switches labelled S1 to S8 which are used in selecting operation modes between absorption and reflection mode. The structure was designed on an FR4 substrate measuring $8.60 \mathrm{~mm}$ by $8.60 \mathrm{~mm}$ with a thickness of $1.60 \mathrm{~mm}$. Other properties of the substrate include relative permittivity of 4.4 and loss tangent of 0.019 . The structure has a full ground plane to minimize transmission. Figure 1(a) shows the proposed structure with the copper wire switches (S1 to S8), while Figure 1(b) shows the structure with absorber configuration while Figure 1(c) shows it with reflector configuration. The structure's primary resonance for both absorber mode and reflector mode configuration is at $10.20 \mathrm{GHz}$.

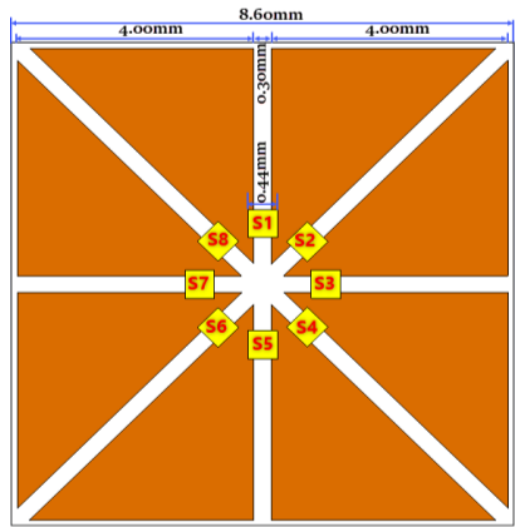

(a)

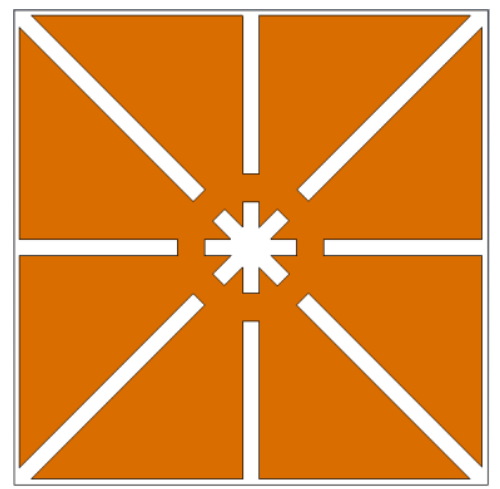

(b)
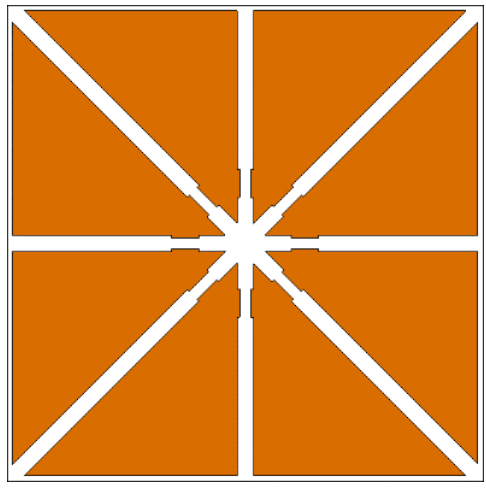

(c)

Figure 1. Proposed structure showing, (a) Switches S1-S, (b) Absorber mode configuration,

(c) Reflector mode configuration

The simulations of the proposed structure were carried out using Microwave Studio of Computer Simulation Technology CST® 2019. For both absorber and reflector configurations, boundary conditions were set to "unit cell" while $\mathrm{Z}_{\min } \& \mathrm{Z}_{\max }$ were set to "open add space". Reflector's reflection was taken from the return loss $S_{11}$ while absorbance, $A(\omega)$ was calculated using $A(\omega)=-R(\omega)-T(\omega)$. Where reflectance, $R(\omega)$ is $|\mathrm{S} 11|^{2}$ and transmittance, $\mathrm{T}(\omega)$ is $|\mathrm{S} 21|^{2}$. Transmittance was zero $|\mathrm{S} 21|^{2}=0$ since the structure has a full ground plane. As mentioned, the structure's primary resonance for both absorber mode and reflector mode configuration is $10.20 \mathrm{GHz}$. In addition to that, the incident wave angle was varied from 0 to 50 degrees, and the results were reported.

\section{RESULTS AND DISCUSSION}

\subsection{Absorber's operations analysis and absorption mechanism}

As mentioned earlier, the structure can performer as an absorber or a reflector, depending on the selected configurations. Over here, the structure is set to work as an absorber where it resonates at 10.20 GHz. The absorber configuration is accomplished by activating the copper switches. Activating the copper switches results in the formation of circular ring-like shape at the centre of the structure. This disrupts the diagonal surface current; thus, creating a pendulum moment around the newly made circular shape structure. With this regard, the switch tends to be the primary absorption mechanism as it establishes a new path for the surface current and thus giving rise to the resonance.

The TE and TM absorption performance of the structure is discussed here. Due to the nature of the design, the structure is polarization insensitive. Therefore, both TE and TM modes analysis were identical. It was observed that for incident wave less than 20 degrees, the structure achieved not less than 99\% absorption. As the incident angle was increased, between 21 and 40 degrees, the structure demonstrated more than $93 \%$ absorption. As the incident wave angle was further increased to above 40 degrees, 
the performance of the structure dropped even further to $87 \%$. The waveforms obtained from the TE and TM mode simulations are shown in Figures 2(a) and (b) respectively.

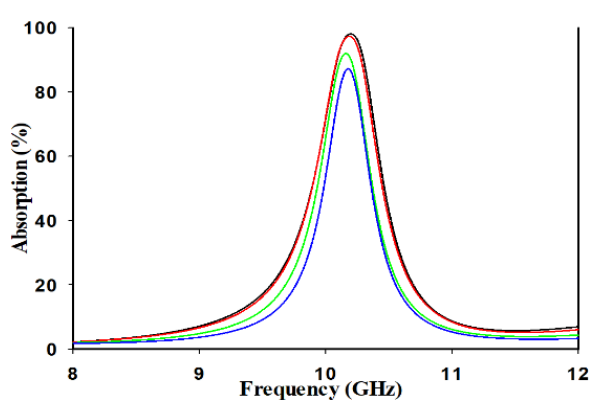

(a)

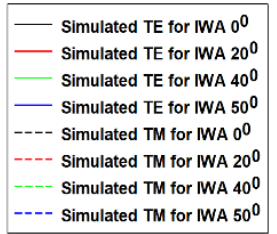
---- Simulated TM for IWA $50^{\circ}$

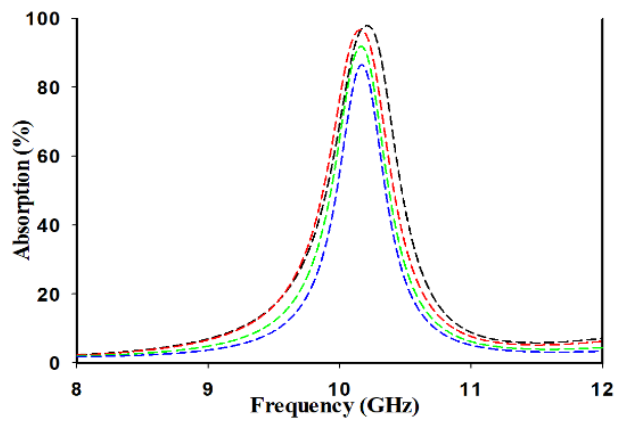

(b)

Figure 2. The waveforms simulation at different incident wave angles, (a) TE-mode absorption,

(b) TM-mode absorption

\subsection{Reflector's operations analysis}

Over here, the structure was configured to work as a reflector. This configuration is achieved by removing or deactivating the switches $\mathrm{S} 1$ to $\mathrm{S} 8$. This action results in creating a free flow path for the surface current and thus reducing the electromagnetic coupling at the centre of the structure as in the case of the absorber. This also, in addition, breaks down the circular-shaped structure formed by the switches. This makes the capacitance at the edge of the structure to be more active and thus results in displaying reflection characteristics.

\subsubsection{TE and TM reflection performance at different incident wave angles}

Similarly, in this case, the TE and TM performance are identical. For both TE and TM mode, the structure demonstrated not less than $89 \%$ reflection for incident wave angles between 0 degrees and 20 degrees. As the incident angle was increased to 40 degrees, the performance slightly dropped to $83 \%$ while the resonance shifted to the right (from 10.20 to $10.209 \mathrm{GHz}$ ). Furthermore, as the incident wave angle was increased to 50 degrees, the reflection dropped to $79 \%$. Similarly, the resonance shifted further to 10.221 GHz). The reflection waveforms are shown in Figures 3(a) and (b) respectively.

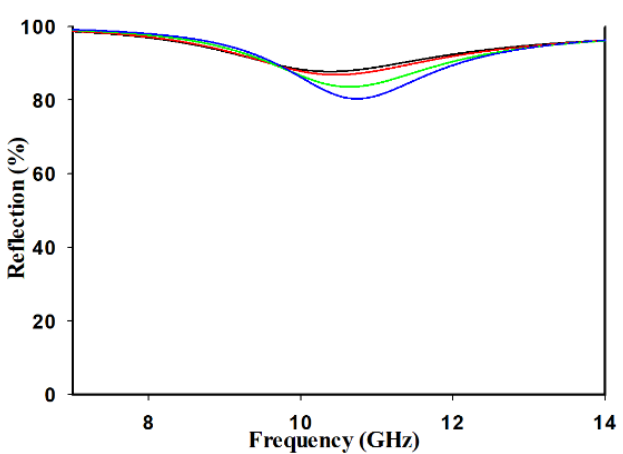

(a)

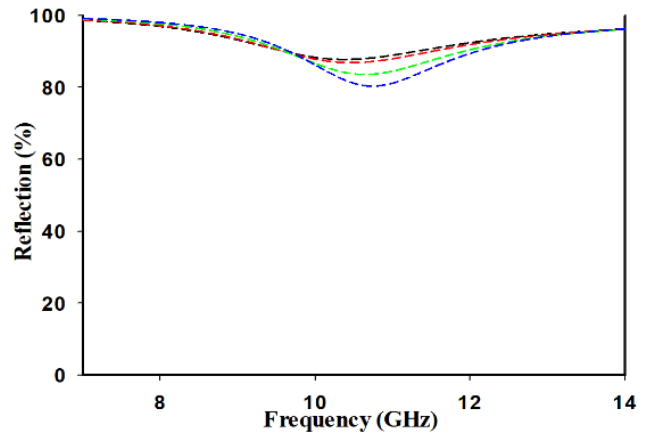

(b)

Figure 3. The reflection performance waveforms at different incident wave angles (a) TE-mode reflection, (b) TM-mode reflection

\subsubsection{TE and TM reflection phase at different incident wave angles}

Over here, the reflection phase of the structure is discussed. It is worth mentioning that for a reflector, the reflection phase is vital. That is because the in-phase image is only produced within the phase ( -180 to +180 degrees), at angle 0 degree, whereas the usable bandwidth of the structure is taken from (-90 to +90 degrees). 
Having that in mind and recalling that the structure is polarization insensitive. It is expected that the TE and the TM mode simulations results will be identical. For the incident wave angle 0 and 20 degrees, the structure demonstrated a usable bandwidth of $3.327 \mathrm{GHz}$ (from 8.628 to $11.955 \mathrm{GHz}$ ) and $3.196 \mathrm{GHz}$ (from 8.781 to $11.977 \mathrm{GHz}$ ) respectively. For incident wave angles 40 and 50 degrees, the structure demonstrated usable bandwidth of $2.688 \mathrm{GHz}$ (from 9.210 to $11.898 \mathrm{GHz}$ ) and $2.273 \mathrm{GHz}$ (from 9.533 to $11.806 \mathrm{GHz}$ ) respectively. It was noted that the drop-in reflection and shift in resonance results in reduction of the usable bandwidth. The reflection phase waveforms are shown in Figures 4(a) and (b) respectively.

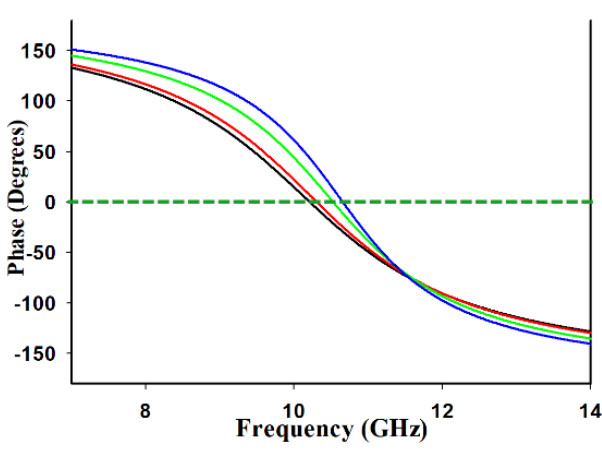

(a)

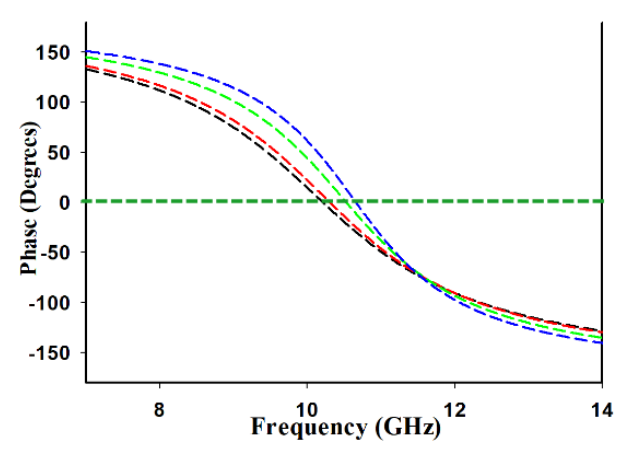

(b)

Figure 4. The reflection phase waveforms at different incident wave angles, (a) TE-mode reflection,

(b) TM-mode reflection

\section{CONCLUSION}

A polarization-insensitive switchable metamaterial Absorber /Reflector for X-band application is presented. The structure's performance was tested with varied incident wave angle from 0 to 50 degrees, and the results were reported. The structure under absorber mode configuration achieved almost a $100 \%$ absorption with a minimum of $87 \%$ absorption at incident wave angle 50 degree. It demonstrated a percentage bandwidth of $3.314 \mathrm{GHz}$ at $80 \%$. On the other hand, under reflector mode configuration, the structure demonstrated almost a $90 \%$ reflection with usable bandwidth of $3.327 \mathrm{GHz}$. The structure has potentials for X-band applications such as stealth and visibility modes for military

\section{ACKNOWLEDGEMENTS}

The authors would like to thank the Ministry of Education (MOE), School of Postgraduate Studies (SPS), Research Management Centre, Advanced RF and Microwave Research Group, School of Electrical Engineering, and Universiti Teknologi Malaysia (UTM), Johor Bahru, for the support of the research under Grant 06G15 and 04G67. The authors also would like to acknowledge all members of the Advanced RF and Microwave Research Group (ARFMRG).

\section{REFERENCES}

[1] N. I. Landy, S. Sajuyigbe, J. J. Mock, D. R. Smith, and W. J. Padilla, "Perfect metamaterial absorber," Physical Review Letters, vol. 100, no. 20, p. 207402, 2008.

[2] A. Sihvola, "Metamaterials in electromagnetics," Metamaterials, vol. 1, no. 1, pp. 2-11, March 2007.

[3] A. Sihvola, "Metamaterials: A personal view," Radioengineering, vol. 18, no. 2, pp. 90-94, 2009.

[4] H. Chen, B.-I. Wu, and J. A. Kong, "Review of electromagnetic theory in left-handed materials," Journal of Electromagnetic Waves and Applications, vol. 20, no. 15, pp. 2137-2151, 2006.

[5] Y. J. Kim, Y. J. Yoo, J. S. Hwang, and Y. P. Lee, "Ultra-broadband microwave metamaterial absorber based on resistive sheets," Journal of Optics, vol. 19, no. 1, p. 015103, 2016.

[6] S. S. Islam, M. R. I. Faruque, and M. T. Islam, "Design and absorption analysis of a new multiband split-S-shaped metamaterial," Science and Engineering of Composite Materials, vol. 24, no. 1, pp. 139-148, 2017.

[7] M. J. Hossain, M. R. I. Faruque, and M. T. Islam, "Design and analysis of a new composite double negative metamaterial for multi-band communication," Current Applied Physics, vol. 17, no. 7, pp. 931-939, 2017.

[8] S. N. Burokur, M. Latrach, and S. Toutain, "Analysis and design of waveguides loaded with split-ring resonators," Journal of Electromagnetic Waves and Applications, vol. 19, no. 10, pp. 1407-1421, 2005.

[9] V. Veselago, L. Braginsky, V. Shklover, and C. Hafner, "Negative refractive index materials," Journal of Computational and Theoretical Nanoscience, vol. 3, no. 2, pp. 189-218, April 2006. 
[10] C. T. Chan, J. Li, and K. H. Fung, "On extending the concept of double negativity to acoustic waves," Journal of Zhejiang University SCIENCE A, vol. 7, no. 1, pp. 24-28, 2006.

[11] M. D. Gregory, J. A. Bossard, Z. C. P. O. Morgan, C. S. Cicero, J. A. Easum, J. D. Binion, D. Z. Zhu, C. P. Scarborough, P. L. Werner, D. H. Werner, S. Griffiths, M. Ketner, and J. Pompeii, "A low cost and highly efficient metamaterial reflector antenna," IEEE Trans. on Antennas and Propagation, vol. 66, no. 3, pp. 1545-1548, 2018.

[12] M. Gajibo, M. K. A Rahim, N. A. Murad, O. Ayop, and H. Majid, "Switchable wideband metamaterial absorber and AMC reflector for X-band applications and Operations," TELKOMNIKA Telecommunication Computing Electronics and Control, vol. 16, no. 4, pp. 1535-1541, 2018.

[13] J. C. Rautio, "EM filter design success: The fast way," Microwave Journal, vol. 58, no. 2, p. 84, 2015.

[14] M. U. Afzal, K. P. Esselle and A. Lalbakhsh, "A metasurface to focus antenna beam at offset angle," 2018 2nd URSI Atlantic Radio Science Meeting (AT-RASC), pp. 1-4, 2018.

[15] S. Raza, M. A. Antoniades, and G. V. Eleftheriades, "A compact low-profile high-impedance surface for use as an antenna ground plane," 2011 IEEE International Symposium on Antennas and Propagation (APSURSI), pp. 1832-1835, 2011.

[16] F. Li, P. Chen, Y. Poo, and R. Wu, "Achieving perfect absorption by the combination of dallenbach layer and salisbury screen," 2018 Asia-Pacific Microwave Conference (APMC), pp. 1507-1509,2018.

[17] X. Fang, C. Y. Zhao, and H. Bao, "Design and analysis of Salisbury screens and Jaumann absorbers for solar radiation absorption," Frontiers in Energy, vol. 12, no. 1, pp. 158-168, 2018.

[18] F. C. Seman, R. Cahill, and V. F. Fusco, "Salisbury screen with reduced angular sensitivity," Electronics Letters, vol. 45, no. 3, pp. 147-149, Jan 2009.

[19] H. Torun, S. Sadeghzadeh, H. Bilgin, and A. D. Yalcinkaya, "A suspended array of square patch metamaterial absorbers for terahertz applications," Procedia Engineering, vol. 120, pp. 20-25, 2015.

[20] H. Luo, Y. Z. Cheng, and R. Z. Gong, "Numerical study of metamaterial absorber and extending absorbance bandwidth base on multi square patches," The European Physical Journal B, vol. 81, no. 4, pp. 387-392, 2011.

[21] T. S. Almoneef and O. M. Ramahi, "Metamaterial electromagnetic energy harvester with near unity efficiency," Applied Physics Letters, vol. 106, no. 15, p. 153902, 2015.

[22] Constantine A. Balanis, "Antenna theory-analysis and design," John Wiley \& Sons, USA, 1997.

[23] M. M. Islam, M. T. Islam, Md. Samsuzzaman, and M. R. I. Faruque, "A negative index metamaterial antenna for UWB microwave imaging applications," Microwave and Optical Tech. Letters, vol. 57, no. 6, pp. 1352-1361, 2015.

[24] M. M. Gajibo, M. K. A. Rahim, N. A. Murad, O. Ayop, H.A. Majid, M. Aminu-Baba, and R. Dewan, "Entire $\mathrm{X}$-band region metamaterial absorber and reflector with a microstrip patch switch for X-band applications," Indonesian Journal of Electrical Engineering and Computer Science, vol. 15, no. 3, pp. 1452-1457, 2019.

[25] O. Ayop, M. K. A. Rahim, N. A. Murad, and N. A. Samsuri, "Wideband polarization-insensitive metamaterial absorber with perfect dual resonances," Applied Physic A, vol. 122, no. 4, March 2016.

\section{BIOGRAPHIES OF AUTHORS}

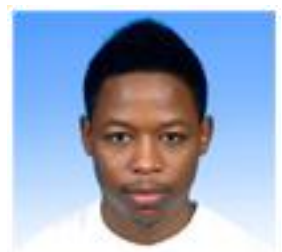

Mohammed Gajibo Mustapha obtained his Diploma in telecommunication Engineering at Multimedia University Melaka (MMU) in 2009. He then obtained his first degree in Electrical/Electronics Engineering at the University of Sunderland U.K (UOS) in 2013. He further obtained his Masters MEng in Electrical and Telecommunication Engineering at Universiti Teknologi Malaysia (UTM) in 2015. He is currently rounding up his $\mathrm{PhD}$ in the field of metamaterial absorbers and reflectors at UTM.

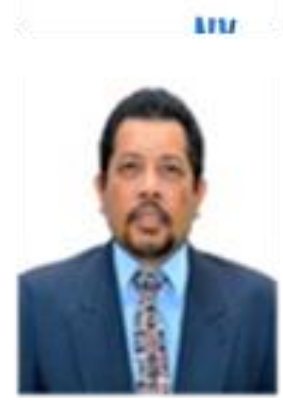

Mohamad Kamal A. Rahim is a Professor at School of Electrical Engineering, Universiti Teknologi Malaysia (UTM). He graduated with a Bachelor of Electrical Engineering from the University of Strathclyde, UK (1987), a Master of Electrical Engineering (Communication) degree from the University of New South Wales, Australia (1992) and a Doctor of Philosophy (Electrical Engineering) from the University of Birmingham, UK (2003). His research interest includes the areas of design of Dielectric resonator antennas, microstrip antennas, small antennas, microwave sensors, RFID antennas for readers and tags, Multi-function antennas, microwave circuits, EBG, artificial magnetic conductors, metamaterials, array antennas, wearable antennas, textile antenna, smart antennas, computer-aided design for antennas and design of millimeter frequency antennas for $5 \mathrm{G}$. He has published over 400 articles. He has supervised more than 20 $\mathrm{PhD}, 50$ Master which includes thesis, project report, dissertation and more than 100 undergraduate students, $10 \mathrm{PhD}$ and 50 Master students have been graduated through his supervision. 


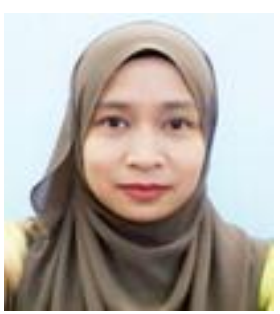

Noor Asniza Murad obtained her first degree in 2001 from Universiti Teknologi Malaysia (UTM), Malaysia, with Honours, majoring in telecommunication engineering. Shortly after graduated, she joined UTM as a tutor attached to the Department of Radio Communication Engineering (RaCED), Faculty of Electrical Engineering (FKE), UTM. She received her MEng. in 2003 from the same university and later has been appointed as a lecturer in April 2003. She joined Emerging Device Technology Group, University of Birmingham, UK and obtained her PhD in 2011 for research on micromachined millimeter wave circuits. Her research interests include antenna design for RF and microwave communication systems, millimeter wave circuits design, and antenna beamforming. Currently, Noor Asniza Murad is a member of IEEE (MIEEE), Member of Antenna and Propagation (AP/MTT/EMC) Malaysia Chapter, and a Senior Lecturer at Faculty of Electrical Engineering, Universiti Teknologi Malaysia (UTM).

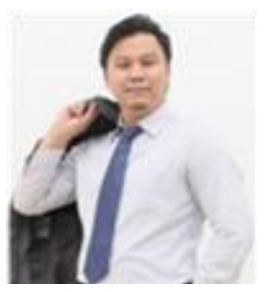

Osman Ayop has received his PHD in Electrical Engineering (2016), master in Electrical Electrical (2010) and first degree in Electrical Engineering-Telecommunication (2007) from Universiti Teknologi Malaysia. He was also done his attachment in Uppsala University of Sweden (2013) under the supervision of Prof. Dr Vernon Cooray in AmstrongLab during the winter semester. His research interests are in the field of antennas, propagation, and also metamaterials. He has been published numerous of journals, proceedings, research books, and book chapters. $\mathrm{He}$ also won several university and national awards related to his research works. He has been appointed as a reviewer for several national/international journals and conferences. He is also an active researcher in Advanced RF and Antenna Research Group (ARFMRG) and has been participating in a lot of courses, seminars, exhibition etc. He has been appointed as a Senior Lecturer in Faculty of Electrical Engineering UTM from 5 April 2016 until today. Previously, he is a Tutor in Department of Communication Engineering, Faculty of Electrical Engineering (Now known as School of Electrical Engineering, Faculty of Electrical), Universiti Teknologi Malaysia from 28 April 2008 until 4 April 2016.

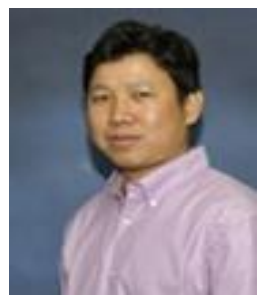

Sunti Tuntrakool is an Assoc Professor at the Department of Engineering Education, Faculty of Industrial Education and Technology King Mongkut's Institute of Technology at Ladkrabang Thailand. He received his PhD degree in electrical engineering at Vanderbilt University, his, M.S. degree in electrical engineering from Vanderbilt University, Nashville TN, in 2004. While his B.S. degree in industrial education in telecommunication engineering major from King Mongkut's Institute of Technology Ladkrabang, Ladkrabang, Bangkok, Thailand, in 1993. His research interests include digital signal processing, biomedical signal processing, mouse renal sympathetic nerve activity, and autonomic control of the cardiovascular system.

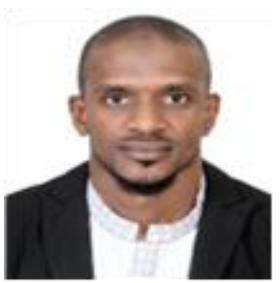

Murtala Aminu-Baba obtained his first degree in 2010 from Abubakar Tafawa Balewa University Bauchi, Nigeria (ATBU) in Electrical/Electronics Engineering. He further received his MSc. Degree in Information Technology from the University of Wolverhampton, U.K, in 2013. $\mathrm{He}$ is currently pursuing his $\mathrm{PhD}$ in the field of metamaterial antenna design for MIMO applications and have been with Abubakar Tafawa Balewa University Bauchi since 2014 as a lecturer.

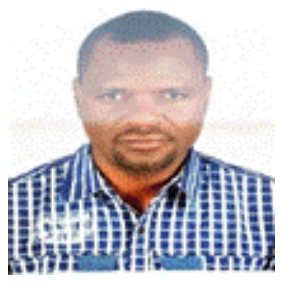

Adamu Yau Iliyasu obtained BEng. in Electrical Engineering from Kano. University of Science \& Technology, Wudi in 2007, Obtained MSc in Electrical \& Computer Engineering in Meliksah/Erciyes University Turkey 2014. Currently PhD Student in Universiti Teknologi Malaysia. School of Electrical Engineering. Malaysia. Johor, His research area is Frequency Reconfigurable Metamaterial Antenna Design. Have been with Kano University of Science and Technology Wudil since 2011 as lecturer.

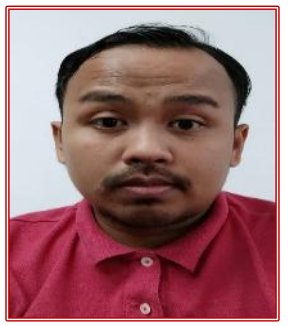

Mohd Ezwan Jalil is studying PhD in Electrical Engineering (2014). He has received in master in Electrical Electrical (2013) and first degree in Electrical Engineering -Telecommunication (2010) from Universiti Teknologi Malaysia. He also did his internship in Rennes University (2014) under the supervision of Prof. Dr Himdi. His research interests are in the field of wearable antennas, chipless RFID, and metamaterials. He published numerous journals such as Applied Physic, Progress in Electromagnetic Research, proceedings such as International Symposium on Antennas and Propagation (ISAP) and European Conference on Antennas and Propagation. He also won several university and national awards related to his research works of wearable antenna. He has been appointed as a reviewer for several national/international journals such as IEEE access. He is also an active researcher in Advanced RF and Antenna Research Group (ARFMRG) and has been participated in a lot of courses, seminars, exhibition etc. 